\title{
Moving from Service to Sustainable Services: A Healthcare Case Study
}

\begin{abstract}
Purpose:

Worldwide, healthcare systems struggle to sustain the delivery of services at a time of increasing demand, limited resources and growing expectations from users. Coupled with dealing with the aftermath of the Covid-19 pandemic and the threat of other outbreaks. There has never been a more important time to sustain innovation and improvements. Using an illustrative case, we assess the application of two existing frameworks to identify the key propositions and dimensions required to deliver sustainable services.

Design/methodology/approach:

This illustrative case study focuses on a service provided by a chronic disease, multi-disciplinary community healthcare team in the UK. Experienced-based interviews were conducted with health professionals, patients and relatives to provide a rich account of a care pathway design. A highlevel process map is used to visualise the key 'touch points.

Findings:

We identify all seven propositions of the SERVICE framework being present along with additional dimensions relating to sustaining innovation and improvement.

Research limitations/implications:

This research is limited to a chronic disease care pathway. However, we believe the results could be applicable to other medical conditions, which are supported by a similar multi-disciplinary service model.

Practical implications:

We provide a sustainable public service operations SERVICES framework for health professionals and managers to consider when (re)designing care pathways.

Originality/value:

This research contributes to the emerging discipline of public service operations research by empirically testing for the first time the SERVICE framework within healthcare. We have included additional factors associated with innovation and improvement and recommended further development of the framework to include factors, such as economic sustainability, highly relevant to the context of universal healthcare systems.
\end{abstract}

Keywords: public service operations, healthcare, sustainability, improvement, service, innovation 


\section{Introduction}

The ability to redesign sustainable services is paramount to the future delivery of effective and efficient healthcare worldwide. In the UK, this challenge coincides with policymakers and the public's fascination and possible anxieties of how public services are being delivered in times of uncertainty, particularly in light of the Covid-19 pandemic and the threat of other outbreaks. We argue that general operations management concepts, tasks and components are relevant to this sector but also, public sector organisations need to recognise that they are a service organisation and therefore need to engage with service operations management theory and frameworks. Operations management (OM) methodologies are 'context specific' and this means that the discipline needs to adapt, rather than dismiss, the context (Radnor and Osborne 2013). How this is achieved is not evident in the OM literature. Similarly, guidance for organisations to deliver sustainable services is variable.

The context of this case research is a community-led service for a chronic long-term disease delivered within a region of the UK. The aim of the paper is to assess the application of Osborne et al's (2015) SERVICE framework to progress our understanding of improving healthcare operations. We believe this is the first application of this framework within healthcare This research is timely given healthcare systems globally are dealing with unprecedented levels of

uncertainty. It is more important than ever that improvements and innovations in healthcare delivery of sustained. We have therefore extended the SERVICE framework to include dimensions of sustainable innovation and improvement as defined by Piercy and Brammer (2012).

We use an illustrative case to test the application of this new combined framework to identify the 
key propositions and dimensions required to deliver sustainable services. This research also makes an important practical contribution as healthcare professionals and managers endeavour to (re)design and deliver sustainable services in what is a complex and challenging environment.

The remainder of this paper is organised as follows: the next section briefly discusses the trajectory of service operations management research and the importance of public service operations management. Then an overview of the original SERVICE framework and the dimensions of sustainable of improvement is provided. The methodology section reports on the design of the case research, followed by the results and discussion. The paper concludes with the limitations of the study and opportunities for further research.

\section{Trajectory of public service operations management}

The discipline of operations management has its origins within manufacturing. However, with the growth of the service industry came service operations. Periodically scholars call for more operations management research in not-for-profit and Public Sector organisations (Karwan and Markland 2006, Taylor and Taylor 2009), because increasingly the fragmented and interorganizational context of public services delivery (Haveri, 2006) necessitates asking new questions about public services delivery. As a result, we have seen the introduction of professional services followed by public service operations management (Radnor and Bateman, 2016). The emphasis on public services may have been fueled by the fact during the period of 2005 to 2011, both the UK and US, as well as other countries such as Greece and Portugal, have experienced unprecedented financial crisis across public sector service which has led to severe spending cuts. Given the recent Covid-19 global pandemic, it is likely this crisis will continue as healthcare systems face the uncertainty of possible second waves of the pandemic and 
the need to resume key services.

Such continual pressure on the western world public services has forced the need to reduce costs and increase efficiency. This has led to many organisations adopting private sector management concepts in order to improve their internal operations and processes. One area of public services operations management that has received more attention of late is healthcare. Studies have explored how approaches and techniques originating from manufacturing are applied within healthcare systems in order to improve health outcomes and the efficiency and effectiveness of care delivery (Henrique and Filho, 2020; Green, 2012). Froehle and Magazine (2012) propose operations management and operations research has a lot to offer healthcare operational decision making with direct benefits including reduced patient waiting times, better access to care and cost savings.

\section{Sustainability and improvement of public service operations}

The work of Osborne et al., (2015) builds the case for an integrated context for which public service organisations, such as healthcare organisations, to entrench sustainable business practice. In the development of the SERVICE framework, the authors eloquently review and comment on the last decade's emerging strand of public management theory. Although the scope of this paper is not to repeat this conversation, we do draw on their SERVICE framework (see figure 1) (Osborne et al., 2015), which embraces service-dominant logic rather than the product dominantlogic so often imposed on public and professional services (see Osborne et al., 2013). 
The interest and implementation of quality improvement approaches has been one area of public service operations that has gained momentum over the past decade. This interest has spanned various sectors including Health (e.g. Brandao de Souza, 2009; Papadopoulos et al., 2011), Central and Federal Government (Richard 2008, Radnor, 2010) and, Local Government (Krings et al. 2006, Seddon and Brand 2008). Approaches have included Lean Thinking, Six Sigma, Business Process Reengineering (BPR), Kaizen and Total Quality Management as well as blended approaches such as Lean Six Sigma. Reviewing the trajectory of these approaches in healthcare confirms this rise in the use of quality improvement. For example, in 2010 a review of the use of business process improvement methodologies in the public sector reported $51 \%$ of publications focused on Lean, with 35\% of these being in health services (Radnor 2010). In 2015, a review identified 243 articles associated with implementing lean in healthcare, with acute settings (hospitals) being the most prominent in the literature (D'Andreamatteoa et al., 2015). A more recent review of the use of Lean in healthcare identified 605 publications with 237 of these reporting on the implementation of Lean projects (Wackerbarth et al, 2020). From this latest review, the authors concluded there was low adherence to the tenets of Lean, which suggests issues with the fidelity of implementation and sustainability of improvements.

Some authors have reported on the mixed results of improving healthcare services (Proudlove et al., 2008; Radnor et al., 2012). Some reports have shown some encouraging signs, for example, Burgess and Radnor's (2013) study of English NHS Hospital Trusts reported a movement from project based improvement to more systemic change. However, they did question the sustainability of the improvements. Sustainability is the focus of this paper both in terms of the design of the service and the innovations and improvements made. We draw on two theoretical frameworks to analyse our healthcare case research. The SERVICE framework (Osborne et al., 
2015) focuses on the sustainability of public services and the second on improvement and innovation (Piercy and Brammer, 2012).

\section{SERVICE framework}

The role of the service-user in the design, delivery and evaluation of public services continues to gain attention among academics, practitioners and policymakers. Radnor et al (2014), among others, have argued for public services to move away from a product-dominant logic, where production and consumption are separated as discrete processes, to a (public) services-dominant logic where the service experience is placed at the centre of public services delivery (Osborne et al., 2015; Virtanen and Stenvall, 2014).

Similarly, there has been a call for public sector organisations to move beyond the short-term, transactional approach to a relational approach. This emphasizes three elements: building system-wide relationships; understanding sustainability is strongly linked to the transformation of user knowledge; and professional understanding of the delivery process of public services is based upon co-production with service users (Osborne et al., 2015). Gronoos (2007) highlights in the case of services the production process is iterative and production and consumption occur concurrently. From an analysis of the new public management literature, Osborne et al (2015) develop a framework in which sustainable business models for a range of public services can be situated. This is the SERVICE framework, which consists of seven propositions: System, Environment, Relationships, Value, Innovation, Co-Production and Experience (see figure 1). 
Proposition one refers to public service organisations being part of complex service delivery systems. The ability to act as independent units is of limited value and there is a far greater need for negotiated relationships to include policy makers, other public service organisations, service users, citizen and other stakeholders (Osborne et al., 2014). The integrated governance of these organisations is insufficient to support the level of integration needed for complex systems. Healthcare organisations particularly face this challenge of operating within complex service systems where many patients have comorbidities and complex needs. In the UK and elsewhere, there are continual calls for better joined up healthcare services (e.g. The King's Fund, 2015; Williams, 2017; Rechel, 2020).

The second proposition considers the environment and how service organisations embrace and embed organizational sustainability. The sustainability of individual organisations is a prerequisite for the long-term survival of the wider system of public services (Osborne et al 2015). In healthcare, this might refer to the sustained delivery of services within the acute (hospital) and community settings. The introduction of intra-organisational networks (e.g. stroke and cancer care networks) that bring these settings together is just one mechanism that might help to create an environment conducive to embedding organizational sustainability. Other environmental considerations are financial constraints and environmental regulations public service organisations are required to balance.

The third proposition focuses on the importance of relationships within what is a knowledgedriven sector. Technology is providing a platform in which the nature of relationships between public sector organisations, politicians and service users is changing (Osborne et al., 2015). However, the spread and proliferation of fragmented information systems remains (Okemiri et al 
2020). This challenge must be addressed as healthcare systems gradually transform into models of care that are digital and patient-centered. The presence of inadequate data integration at various levels incapacitates key activities such as operational planning, clinical decision-making and patient flow. There is a variety of existing information and communication technologies (ICTs) that can improve the quality and delivery of healthcare services (Gastaldi et al., 2012). One such example is the growing use of radio frequency identification (RFID) technologies with applications including:

- patient identification improving patient safety (Tseng et al., 2008);

- patient tracking used to track movements within a facility to improve the quality and timeliness of services (Swedberg, 2010);

- asset management to ensure the availability of critical equipment (Qu et al., 2011) and;

- medical treatment support with tagging of items such as drugs to endure accuracy of treatment processes (Sun et al., 2008).

There is also a need to move away from short-term transactional relationships (often used within product-dominant settings), (McLaughlin et al., 2009) to develop long-term relationships across service systems (McGuire, 2012). The majority of 'public goods' (whether provided by government, the non-profit and third sector or the private sector) are in fact not 'public products' but rather 'public services' that are integrated into people's lives (Radnor and Bateman, 2016). A collaborative network of organisations, teams and individuals is needed to develop the communication and knowledge to aid seamless transition across this network. Healthcare services are often criticized for lack of coordination and joined up care (Parnaby and Towill, 2009; Sloan et al., 2014). 
Value represents the fourth proposition. In the public management literature that has been some discussion around whether the achievement of public value is an indicator of public service effectiveness rather than internal measures of public service efficiency (e.g. Bekkers et al., 2011; Benington and Moore, 2010). Osborne et al (2015) note this discussion is fundamental to reforming public services. The desire to add value to the lives of citizens and service users is critical to improving the delivery of existing services and the design of new services. Although patient and public engagement has been on the agenda for many years within the NHS (UK) the impact has been disappointing (Coulter, 2012). In particular, there has been a lack of focus on engaging patients in their own clinical care, despite strong evidence that this could make a real difference to health outcomes (Coulter, 2012). A useful addition to the discussion around cocreating value comes from Black and Gallan (2015) who advocate healthcare service networks can enhance communication and the co-creation of value. Such networks can include individuals, groups or organisations (Vanden Bulte and Wuyts, 2007). However, understanding value, rather than satisfaction, from the perspective of patients, relatives and health professionals remains underdeveloped within healthcare. More recently, there has been a call for a broader conceptualization of value (Black and Gallan, 2015) which includes a holistic definition of wellbeing (e.g. emotional, physical and psychological health or life satisfaction (Ballantyne and Varey, 2006).

The fifth proposition refers to innovation, which is a critical factor for the development of healthcare systems (Thune and Mina, 2016). Innovation in healthcare can be classified in three ways: product innovation (e.g. medical devices); process innovation (e.g. redesign of patient pathways or technologies to enable integration of health series) and organizational innovations (e.g. new ways of working - interdisciplinary teams). Osborne and Brown, (2011) note that 
public service organizations need to support and develop innovation across the service system to ensure it is effective. For this to be achieved Osborne et al. (2015) propose three conditions to be present. First, the innovation needs to be externally focused to ensure that it adds value to service users rather than solely focusing on internal efficiency. Second, the service user needs to be involved in the process and production of the innovation (Skalen et al., 2014; Verma and Jayashima, 2014). Finally, governance rather than management is essential to the innovation of complex service systems. Proksch et al. (2019) argue innovation in healthcare has, in general, a positive effect on patient outcome and provide examples of healthcare innovation such as textmessaging and mobile-health behaviour change interventions, new process leading to reduction in unnecessary admissions and new generation of transcatheter heart values. One response that has been adopted by around 150 general practices in England is a "telephone first" approach, a practice-wide change in which every patient asking to see a GP is initially phoned back by a GP on the same day (Newbould et al., 2017). It has been claimed this approach lowered the use of emergency departments by up to $20 \%$ and cost savings of about $£ 100000$ per practice through prevention of avoidable attendance and admissions to hospital (NHS England, 2013).

Co-production represents proposition six. Alford (2014) highlights often the lack of understanding of service management where the service user is rarely casted as the co-producer of public services, and is seen as the client of public service agencies. Where possible, users should be able to manage their own journey with providers, commissioners and regulators. Perhaps more accurately for healthcare, Osborne et al., (2016, p640) define co-production as 'the voluntary or involuntary involvement of public service users in any of the design, management, 
delivery, and/or evaluation of public services'. There is a continuum of perspectives on coproduction which includes user involvement being 'added into' the operational process of service delivery to higher levels of co-production due to the consumption and production of the service taking place at the same point (Osborne et al., 2015). There is still much debate over what constitutes co-production and the challenges associated with power relations and questions of representation/inclusivity (Palmer et al., 2018; Williams and Caley, 2020).

There is a growing body of literature on coproducing healthcare services and to some extent may be leading the way, particularly in Mental Health Services. Traditionally, healthcare services have recognized the need for some kind of partnership with patients. For example, in the US the Center for Medicare Services identifies patient and family engagement as a pillar in its efforts to improve healthcare (McCannon and Berwick, 2011). Similarly, in social care participatory delivery of services is actively sought by policy makers (Cayton, 2004; Needham and Carr, 2009). Coproduction is featured in the literature within the context of improving healthcare systems (e.g. see Batalden et al., 2016; Filipe et al., 2017; Kaehne et al., 2018) and is seen as a model of service delivery, which should have a positive impact on service users (patients) and on the wider social system (Realpe and Wallace, 2010). Black and Gallan (2015) extend this discussion to emphasise the importance of organisations within the healthcare system (also referred to a network) to engage with one another to enhance patient well-being and quality of life and to cocreate value with the patient/customer. The final proposition builds on these collaborative efforts by capturing the knowledge from across the healthcare system in order to improve the service experience and to ensure improvements are sustained (Lusch and Vargo, 2006; 2014). Table 1 summaries the theoretical propositions. 


\section{Sustainable SERVICE innovation and improvement}

In addition to the SERVICE framework, we note here the important link between innovation, improvement and sustainability. Piercy and Rich (2015) provide a useful description, which we believe can be assessed within the realms of public services. Although their discussion sits largely within manufacturing, it does encourage us to go beyond the confines of improvement and environmental sustainability, the place where much of this work has focused (e.g. Pil and Rothenberg, 2003; Kleindorfer et al., 2005). Conducting a meta-analysis of several hundred studies, Piercy and Brammer (2012) identified six dimensions related to innovation, improvement and sustainability: environmental; workforce; supply chain; community; governance and quality issues (see table 2).

Insert table 2 here

Considering these sustainable improvement dimensions in light of the SERVICE framework, we draw some similarities between the two approaches (see table 3). First, the whole systems approach is common to the supply chain context required for sustainable improvement. The reference made to embedding organizational sustainability for the short and long-term needs to encompass environmental issue along with arrangements for governance and quality improvement. Long-term relationships are central to both the SERVICE framework and the sustainability dimensions, which may extend across the organisation, supply chain and the wider community. Similarly, the ability to deliver and sustain public value again requires collaborative working. Innovation to achieve service effectiveness can occur in serval ways including 
environment, supply and quality improvements along with new working practices and technologies. Coproduction of a service requires service-user involvement, which may be concomitant to the wider community depending on the service being offered. Finally, the knowledge creation and mobilization required to enhance the service experience can be linked to the internal and external supply chain. Clearly organizational and supply chain structures and governance need to be in place to aid shared learning and decision-making.

\section{Insert table 3 here}

As there are similarities between the SERVICE framework and the dimensions of sustainable innovation and improvement, we employ both approaches in our illustrative case to enable us to assess sustainability in the widest sense.

\section{Methodology}

To test the application of this combined approach, we engaged with a multi-disciplinary specialist team, which was developed to deliver services within the community for patients diagnosed with Huntington's disease (HD). There are between 6,000 and 8,000 people within the UK living with HD (HD Association, 2012). It is a hereditary disorder of the central nervous system and usually develops in adulthood and can cause a very wide range of symptoms. The trajectory of care varies for each patient although the HD Association (HDA) has identified the types of specialisms and services that HD patients are likely to need to access.

An illustrative case study (McNulty and Ferlie, 2002) was employed, as this design is suitable for 
testing of new frameworks and where a limited body of evidence exists (Meredith et al. 1998) often within an under researched setting (Pitchforth et al, 2017) in this case healthcare. The research lends itself to an exploratory approach and an inductive methodology to allow the building of theoretical insights (Yin, 2014) into the sustainability of service design and improvement and innovation activity.

Our illustrative case study focused on a community based HD service within one region of the UK. The case study and participants were purposively selected based on the criteria shown in table 4. The HD multidisciplinary community team consisted of a psychologist, nurse, occupational therapist, physiotherapist and a speech and language therapist. Staff participants were invited to participate in the study by email which included the information sheet. All members of the team participated in the study.

The HD Team lead identified twelve patients and their relatives to join the study. Service user participants needed to have been accessing the service for at least six months. Details of the study were provided to patients and relatives by the lead of HD team. Contact was made by telephone with those that expressed an interest to take participate in the study. All participants needed to be able to provide consent to take part in the study.

Insert table 4 about here

Experience-based, in-depth semi-structured interviews were conducted with all the healthcare professionals within the HD team $(n=5)$. Of the twelve patients invited to participate in the study three agreed along with six relatives/carers. All interviews conducted were face-to-face and audio recorded. We recognize the limited number of participants within the study; therefore, to 
validate the results these shared anonymously with a wider group of HD patients and relatives when attending family group meetings.

The duration of the interviews was between 30 and 60 minutes and all were audio recorded with the consent of the interviewees. Interviews took place in the interviewee's home (patient and relatives) or place of work (healthcare professionals). The main aim of this study was to test the application of SERVICE propositions and improvement/innovation dimensions to enable us to assess if the HD care pathway is sustainable. To gain an in-depth understanding of how the care pathway is operationalised we asked the interviewees to recall their experiences of either giving or receiving care. Healthcare professionals were asked about their roles within the pathway, when and how the service was introduced, how the service is delivered and evaluated and any recent changes made. Patients and relatives were asked to share their experiences of receiving care from the HD team and other providers. All interviews were transcribed verbatim. A twostage approach was used to analyse the data:

1. Interview data documenting the experiences of staff, patients and relatives were triangulated and analysed to produce a high-level process map of the service (see figure 2). This map was validated with members of HD family group to confirm the service design and any recent or required innovations and improvements.

2. An inductive thematic analysis of the interview data was also conducted using King's (1998; 2004) thematic framework. This approach encourages an iterative process where the coding framework develops as interviews are analysed. Themes were matched against the propositions of the SERVICE framework and dimensions of sustainable innovation and improvement (see table 5). Additional areas associated with service delivery and improvement were included in the coding framework. 
Extracts from the interviews are included in the analysis to illustrate the experiences of those delivering and receiving care.

\section{Insert table 5 here}

\section{Results and discussion}

A high-level process map (see figure 2) was constructed, which identifies the interventions and touch points within the Huntington's disease (HD) patient pathway. The map provides a roadmap of the patient journey and identifies the different stakeholders involved in delivering care and services for HD patients. It is likely, in the UK, there are regional and national variations depending on how HD services are commissioned. However, the map illustrates the key 'touch points' for those involved in receiving and giving care which is helpful for our discussions around the sustainability of the service. Touch points relate to the key stages of transition within a patient pathway usually from referral to treatment (or care management) whether in a hospital or community setting (Williams and Radnor, 2017). From our research, we know that not all HD services are provided by community-based multi-professional teams as in our case research, and therefore this might be seen as an exemplar service.

Insert Figure 2 here - High-level process map of HD patient care pathway

From our analysis, we were able to identify all seven propositions of the SERVICE framework, with some more prominent than others. The multi-professional, user-centred approach to the design and delivery of the HD service has presented an innovative and sustainable approach. 
Here we examine each proposition in turn by synthesizing our data and including extracts from the interviews where appropriate.

The first SERVICE proposition refers to the notion public services are not just organizations but are in fact systems and need to be governed as such. From the interviews with the HD health professionals, it was evident that their work expanded well beyond the clinical interventions required by their patients. The team is responsive to what is required to keep the patient functioning and living an independent life where possible. The flexibility of the team is a key attribute as one staff interviewee noted, "we go wherever the patient is, this can be their home, nursing home, day care unit or hospital." The span of communication extends across organizational and professional boundaries, but interestingly this is not dependent on technological solutions. The multi-professional roles of the team enable them to provide an integrated service which includes outreaching and working collaborating with a spectrum of health and social services. Often this means participating in activities such as form-filling, accompanying patients and relatives to interviews and meetings, and making telephone calls on behalf of patients and relatives, as one relative interviewee remarked, "they've been so much help with all this paperwork because I'd be no good at it". Another patient interviewee recounted the difficulties of getting rehoused and how the team assisted him "I was on it (the council housing list) for two years.. and still heard nothing, then [name of team member] got involved and we applied again .. it was three months and everything was done."

The HD team operate well-beyond the boundaries of their professional roles and collectively provide information and assistance that helps their patients remain independent for as long as possible and to make the transition across the various agents within the health and social care 
system/network as seamless and well integrated as possible. This level of interaction across the different services enables the HD team to optimize their service provision and effectively engage in value co-creation with their patients (Black and Gallan, 2015).

The weekly HD team meeting is also integral to enabling this system/network approach to be managed and sustained. Collectively the team is able to draw on their shared experiences and knowledge to ensure signposting is up-to-date and accurate. Blurring of the different professional roles is inevitable to enable the team to be responsive to patient and family needs. As one staff interviewee noted "If it was say an occupational therapy referral but $\mathrm{xxxx}$ is inundated with work for three weeks or so, again, we would make that multi-disciplinary decision. The team meeting is fundamental to ensuring clarity around responsibilities and information sharing.

The second proposition is the need to develop an environment conducive to organizational sustainability both in the short and long term. One area this relates to is the need to maintain the employment of the staff and managers. Here our unit of analysis is the patient pathway and central to this as noted above is the multidisciplinary working by the team. All the HD team members had been in their roles for at least 2 years. The team lead had been in post for approximately 7 years, shortly after the team's inception. The maturity and experience of the team assists in creating a stable environment and embedding the service within the wider organization. One staff interviewee noted, "the professions of the team are carefully selected to reflect the needs of our patients and their families. We review this regularly to ensure that we have the right skills." 
The other element of sustainability to be considered is (health) service sustainability, in particular the need to move away from service silos to create an integrated service. To some extent, the multi-disciplinary nature of the team and the collaborative working environment has enabled them to blur the professional boundaries that might be more evident in clinical teams. For example on staff interviewee noted how any member of the team can undertake the initial assessment “...to respond more quickly, somebody else would go out and do the core assessment. And then the assessment process would start". The wider integration across the health and social care system (network) probably requires further examination. It is evident members of the team are acting as 'brokers or boundary spanners' (Long et al., 2013) to bridge organizational boundaries and ensure consistency of service delivery. Continually negotiating the access to services on behalf of patients along with ensuring client information from other providers is current and informative. This often extends to accompanying patients and relatives to interviews and meetings to enable them to access support (e.g. accessing care in the community) across the wider health and social care system. Often this support can extend to the wider public service system (e.g. housing, education, benefits) which can assist the general wellbeing and independent living of patients and their relatives. Several of the patient and relative interviewees spoke about receiving help with obtaining bus passes and disabled badges and in one case access to financial support and benefits.

The third proposition requires the development of long-term relationships across the service system rather than seeking short-term transactional value. The progressive nature of HD requires patients and their families to seek support at various points of the disease trajectory. It is difficult to predetermine what support will be required and when due to the complexity of the condition. However, given the stability of the team membership it has allowed good relationships to be 
developed with their patients/relatives. One relative interviewee stated how she and members of her family had developed strong relationships with the team and how the team was usually her first port of call when seeking advice. Similarly, as the team liaises with other service providers such as social care they are also developing good relationships across the care supply chain. One relative interviewee stated the "team is so ... experienced and familiar with individuals and with the whole general situation, and with all the social issues, we have very little contact with our GP regarding HD." Another staff interviewee referred to the good relations with other service providers “we've got good relationships actually, we've got very good relationships with local Social Services, and I think again, because our patients have got you know, it's a longstanding disease, those relationships build up over time, so you get to know the social worker, they get to know you." The development of these relationships is dependent on local knowledge of services and hence any changes of personnel within these services need to be communicated. Staff interviewees mentioned the necessity of being kept informed of any changes in service provision or staff to ensure quick and reliable access to appropriate assistance for their users. The formal communication channels to update changes within the system were reported as often being too bureaucratic and slow to react, hence the teams' reliance on more informal relations that are developed at a local level.

The development of new technologies and digital platforms within healthcare is reported to have created interesting opportunities for e-health and connect users, experts and practitioners (Presti et al., 2019). Yet for the HD team the interface between IT systems is often problematic even within a community and acute setting of the same organisation (Okemiri et al 2020). All of the health professionals' interviewees spoke of their frustrations and called for the development of better Information Systems to support the communication required by these system-wide 
relationships.

Proposition four promotes the need for internal efficiency (e.g. quality improvement) and the ability to have an outward-facing focus on value. The HD team meets weekly to review the needs of their existing patients and any new referrals that have been received. All of the health professional interviewees thought this face-to-face meeting was central to being able to respond quickly to the needs of their patients and families. As noted above, the team link regularly with other agencies and service providers to ensure that their patients are able to access services. Sometimes this will involve accompanying the patient to a meeting and other times it will require signposting to available resources. The HD team is continually updating their knowledge of new services and provision within their geographic area. Periodically, the team review their internal systems and procedures to look how they might improve the efficiency and effectiveness of their service. One area that we feel is notable for its omission is economic sustainability, which is a lens in which to view value. Given the pressures highlighted in the early part of this paper, we feel this should not be overlooked within the context of sustaining services in healthcare and the need to deliver economic value. The notion of value-based healthcare encourages us to consider how well resources are allocated based on need and how well the resources are used to serve those in need (Gray, 2017). Interestingly this HD team has been able to protect its funding since its inception ten years ago. However, the team lead did emphasize the difficulties in doing so and the need to demonstrate the value they bring to patients and relatives and the wider healthcare community. The team is continually promoting their services to general practices, social services and other providers. The ability to demonstrate effective use of resources, the service quality and financial gains is becoming more important. The effective use of resources is constrained by the capacity of the team. The patient and family group is one mechanism in which to gather 
information on service quality. The ability to show financial savings is more difficult as it is not always clear when the team has prevented an admission to acute (hospital) services.

The fifth proposition relates to innovation as a means through which to achieve service efficiency and effectiveness. Osborne et al., (2015) note this innovation needs to be open and collaborative. Working closely with patients, relatives and various other stakeholders within the community encourages the HD team to be externally focused. The monthly patient and relative support group the team recently introduced is a mechanism in which they can continually monitor whether their services are delivering what is important to their patients and relatives. The ability to undertake other innovations in relation to communication and access to information was constrained by the wider health and public service system. The interface of IT systems within and outside of the healthcare organization was limited and required regional or national investment. Examining the provision of HD services across the UK it is permissible to say that having a dedicated multi-disciplinary team is an innovation as this is not a service widely available to all HD patient and their families.

Technological innovations appeared to be somewhat limited. The team's open referral system was largely reliant on letters, email and telephones. As one staff interviewee described how referrals were processed by the team ".. phoning the referrer, perhaps ringing the patient, getting as much information as possible, and then we would look at booking in an appointment, that would either be via the telephone or that would be via letter." Some members of the team were able to introduce technological solutions to aid communication. Patients and relatives provided examples of using IT particularly those attending the family groups. These included the setting up of Facebook pages and WhatsApp groups as a way of keeping in touch outside of the 
meetings.

Co-production, in the context of this framework, is reported to be the source of effective performance and innovation in public services. From the interview data and the high-level map (figure 1), it is evident that the patient and their relatives are central to the HD service. Initially the front part of the process focuses on referrals into the system. Once the team receives a referral, the appointment of a named care coordinator is made for each patient. From this point, services and interventions are 'pulled' towards the patient depending on their needs. “..that's where we're lucky as a team, in that we've got that flexibility to be able to respond, as and when, but also to make our interventions appropriate really to what the patient's needs are" (Staff interviewee). Another noted her role was about "..empowering people to make their own choices." The care coordinator supports the patient in getting access to other professions and services that will assist in independent living and enhancing quality of life. A member of the team commented "So I, as care coordinator then, would be responsible for pulling in the relevant people, for notifying the GP, the referrer, of what has happened to date. And then also I would be responsible for reviewing that person and that generally ... it is patient specific, you know as in what their needs are".

Recently the team has introduced patient and family support groups, which again ensure that the patient's voice is central to the design of services. These groups provide the opportunity for open discussions on how services might be improved and more specifically to share experiences of those living with HD. Positive experiences for patients and families such as these create opportunities for more engaged efforts over time and the chance to access important resources and engage in more value co-creating behaviours (Black and Gallen, 2015). 
The seventh and final proposition of the original framework is knowledge, which is seen as a key resource to deliver service experience. Understanding service user expectations and the level of service delivery in which to satisfy those expectations are key areas of knowledge that needs to be developed. Knowledge also may be known just within the organization (also referred to as 'sticky' knowledge) and something that needs to be acquired in order to do the job/role. In relation to the HD team, the generation and sharing of 'sticky' knowledge was apparent from the healthcare professionals. For example, sharing knowledge of contacts within local services and charities was important for service provision and the development of new team members. Having regular face-to-face team meetings supported by other forms of communication e.g. email, telephone were important to all the HD team members. One team member indicated weekly team meetings were crucial to being able to respond to patients' needs. Frequent patient-relative group meetings have also ensured service-users are central to the service. One relative/carer interviewee noted how she could be herself at the group meetings and how she does not feel judged as other member will have experienced something similar.

The summary table (table 6) below illustrates examples of how the propositions of the SERVICE framework and the six dimensions of sustainable improvement are present within the HD service.

\section{Insert table 6 here}

Reflecting on our analysis of the SERVICE propositions and the innovation and improvement dimensions in relation to our case research there is a need to comment on how some were more prominent than others. This observation may reflect the context of the research (e.g. HD service) 
or the growing maturity of public sectors with the field of (service) operations management and the sustainability of services. First, the systemic working of the team was certainly prominent in our data. Collectively the HD team has considerable knowledge of the wider health and social care system/network and were actively able to support and signpost their patients. In this brokering role, they are able to transfer and transform information so it is meaningful for their patients and relatives. The development of good relationships was evident not only within the team and the wider health and social care community but also with their patients and relatives, The nature of this chronic long-term disease often requires sustained support to enable long-term relationships to be developed with the families. This family-centred approach enables greater opportunities for involvement with patients and their families and the ability to co-create value (Black and Gallan, 2015).

The experience and maturity of the team was another key determinant in this case. There has been little turnover of staff since its inception. Any expansion of the team has been managed carefully through various mechanisms (e.g. weekly team meetings, coaching and mentoring, connections with local services) which have helped to share the family-centred ethos the team has developed along with the 'sticky' knowledge acquired from working alongside the families and other services involved in their care.

One of Piercy and Brammer's (2012) dimensions, workforce (which we term staff), we feel is worthy of further discussion. It is important to note, in this case research, the HD team perform generic and professional roles. The care-coordinating role enables the pooling of team capacity to ensure contact is made with new patients as soon as possible. Similarly, the coordinator 'pulls in other professions as and when required by the patient or relatives. Given the importance of the 
integrated working and multi-disciplinarity of the HD service, representation of staff requires greater emphasis in sustaining of services. This is pertinent given the retention and attrition issues facing the UK healthcare system, where there is greater acuity for community based services (Buchan et al., 2019). We therefore propose staff as an additional proposition within the SERVICE(S) framework.

\section{Conclusion}

The overall aim of this paper was to test the application of the SERVICE framework and the innovation and improvement dimensions within the context of healthcare services, and more specifically within a community setting. Our case fits the typical characteristics of a professional/public service as being high customer interaction, high customisation and high labour intensity (Schemmer, 1986). Using healthcare we have assessed the combined framework to reflect the specific context of a multi-professional, family centred, community based HD service.

To the best of our knowledge, this is the first time the original SERVICE framework has been tested within a healthcare setting. In addition, this paper extends combines this framework with dimensions of sustainable improvement and innovation to provide a new SERVICES framework. We have identified that economic sustainability needs to be more prominent when assessing healthcare services particularly in periods of uncertainty which many universal healthcare systems are experiencing for various reasons including the recent coronavirus pandemic. As we have noted, such situations also create opportunities for the innovation and improvements which may need to be sustained beyond the pandemic. 
Although our case results are limited to the pathway of one chronic long-term condition, we believe there are general points of learning to other medical conditions where services are primarily located outside of the acute (hospital) setting. Here our unit of analysis is a patient care pathway provided by a specialized community-based team (rather than organization) but we believe this still has relevance. The Huntington's disease (HD) case in this study could be viewed as an exemplar particularly due to the multi-disciplinary nature of the team, and given the push towards integrated services in health and social care we feel this is an appropriate 'test'.

For our case, some framework propositions and dimensions were more evident than others, for example, there is a strong presence of understanding value, developing long-term relationships and co-producing services. This partially relates to the degenerative nature of the disease but also to the design of model of care (e.g. disease specific, multi-disciplinary and community-based). The strengthening of other propositions and dimensions is possible in particular technology to support interaction with families and other services in particular. Innovations in technology seemed to be driven by families. The case does demonstrate process innovation in the way the team is able to adapt their service to the changing needs of their patients and relatives.

We propose there is one additional dimension (staff) that requires attention, particularly given the retention issues facing many healthcare providers in the UK. Following this empirical research in healthcare the public service sustainable framework - SERVICES framework - we propose is shown in figure 3.

Insert figure 3 here 
The SERVICES framework encourages those designing, evaluating or managing services to review the extent to which each proposition/dimension is present. In healthcare, there is a need to have a clearer understanding of service design and categorization of service attributes in order to identify sustainable improvements and innovations. In particular, this framework helps to highlight those propositions/dimensions that seem to receive less attention. For example, understanding value in healthcare often is considered the same as measuring patient satisfaction. Value needs to be clearly defined and care pathways need to be improved based on the knowledge and clinical expertise of care providers and the preferences and needs of patients (Poksinka et al., 2016). Similarly, the scope for innovation needs to expand beyond technology and product innovation. Often to embed new technologies, process innovation needs to occur. The SERVICES framework is designed to support this shift in thinking. The addition of staff is an important addition as sustainable improvements will be dependent on appropriate use of resource and investment in skills and competencies to review service design, assess service attributes and identify opportunities for the introduction of innovations and sustained improvements.

We opened our paper stating public sector organisations need to recognise themselves as service organisations and engage with service operations management theory and frameworks. Here we have further developed a framework that is specific to service organisations. It offers some clarity and guidance on the key dimensions and propositions in relation delivering sustainable services, an area that is not well understand within the literature. Further research is needed however to contextualize the new SERVICES framework in healthcare and other service settings. 
Our study has shown, from the illustrative HD case, it is possible to identify examples of service design and practice that demonstrate sustainability and improvement. Extending the research beyond care pathways to different levels of the healthcare system would be helpful e.g. organization and system/network, along with different health and social care settings. Because of the Covid-19 pandemic, we have seen many examples of innovation at various levels and scale (e.g. building of field hospitals within weeks). Repurposing of theatres for use as intensive care units and online GP consultations are some examples of operational redesign. Some of these improvements and innovations will need to become the new way of working. We propose our SERVICES framework will provide a model for academics and managers in which to assess service design and opportunities for sustainable improvement and innovation.

More generally, this study has identified further research needs to continue to unpack the relevance of operations management frameworks such as design, planning and control, operations strategy, innovation and improvement. Here we have focused on the design, innovation and improvement of sustainable public services. Other frameworks need to be considered within this context. Studying public service operations provides the opportunity for theory building particularly through the rich data provided by qualitative case studies and will help to provide a greater insight into the operational effectiveness required of public services (Esain et al., 2016).

The implications of the study are twofold. First, for managers and healthcare professionals, we have operationalised the seven propositions of the original SERVICE framework and the six dimensions of sustainable innovation and improvement to provide valuable insight for those charged with designing and delivering sustainable healthcare services. The framework provides guidance on the critical factors such as understanding value, supply chain and environmental 
dimensions of improvement that are often overlooked or less evident when improving healthcare services. We have also emphasized the important role of staff in the delivery of sustainable services and advocate for periods of stability in which teams can identify and implement improvements and innovations.

Earlier we called for public sector organisations to recognise they are service organisations and to engage with service operations management theory and frameworks. It is the role of scholars to continue to develop and test these theories and frameworks in different service environments. Here we have contributed to this research agenda by taking a wider perspective on sustainability, which has resulted in the SERVICES framework.

\section{References}

Alford, J. (2014), "The multiple facets of co-production: building on the work of Elinor Ostrom", Public Management Review, Vol. 16, pp. 299-316.

Ballantyne, D. and Varey, R. (2006). "Creating value-in-use through marketing interaction: The exchange logic of relating, communicating and knowing”. Marketing Theory, Vol. 6, No. 3, pp, $335-348$.

Bamford, D. and Griffin, M. (2008), "A case study into operational team working within a UK hospital," International Journal of Operations \& Production Management, Vol. 28, pp. 215237.

Batalden, M. Batalden, P. Margolis, P. Seid, M. Armstrong, G. Opipari-Arrigan, L. and Hartung, H. (2016), "Coproduction in health care", BMJ Quality \& Safety, Vol. 25, No. 7, pp. 509-517.

Bekkers, V. A. Edwards, R. Moody and Beunders, H. (2011), "Caught by surprise? Micro- 
mobilization. New media and the management of strategic surprises", Public Management Review, Vol. 1, No. 1, pp. 1003-1022.

Benington, J. and Moore, M. (2010), Public Value: Theory and Practice. Palgrave Macmillan, Basingstoke.

Black, H and Gallan, A. (2015), "Transformative service networks: cocreated value as wellbeing", The Service Industries Journal, Vol. 35, No. 15-16, pp. 826-845.

Boozeman, B. (2002), "Public-value failure: when efficient markets may not do", Public Administration Review, Vol. 62, pp. 145-161.

Brandao de Souza, L. (2009), "Trends and approaches in lean healthcare”, Leadership in Health Services, Vol. 22, No. 2, pp. 1

Buchan, J. Charlesworth, A. Gershlick, B. and Seccombe, I. (2019), A critical moment: NHS staffing trends, retention and attrition, The Health Foundation: London.

Burgess, N., and Radnor, Z. (2012), "Service improvement in the English National Health Service: Complexities and tensions", Journal of Healthcare Management and Organisation, Vol. 18, No. 5, pp. 594-607.

Burgess, N. and Radnor, Z. (2013), "Evaluating Lean in Healthcare”, International Journal of Health Care Quality Assurance, Vol. 26, No. 3, pp. 220-235.

Coulter, A. (2012), Leadership for patient engagement, The Kings Fund, London. Available at https://www.kingsfund.org.uk/sites/files/kf/leadership-patient-engagement-angela-coulterleadership-review2012-paper.pdf [Accessed 20 $0^{\text {th }}$ July 2020].

Cayton, H. (2004), "Patient-engagement and patient decision-making in England", Paper presented at the Improving Quality of Health Care in the United States and the United Kingdom: Strategies for Change and Action.

D'Andreamatteoa, A. FedericoLegab, L. and Sargiacomoa, M. (2015). Lean in healthcare: A 
comprehensive review. Health Policy, 119, 1197-1209.

Esain, A. Kumar, M. and Williams, SJ. (2016), Reflections and a research agenda in Radnor, Z., Bateman, N. Esain, A. Kumar, M. Williams, S. and Upton, D (Eds), Public Service Operations Management: A research handbook, Routledge, Abingdon, Oxon.

Filipe, A. Renedo, A. Marston, C. (2017), "The co-production of what? Knowledge, values, and social relations in health care." PLoS Biology, Vol. 15, No. 5, pp. e2001403.

Froehle, C. and Magazine, M. (2012), "The state of healthcare in OR/OM", Manufacturing and Service Operations Management, Vol. 14, No. 4, pp.495 -499.

Gastaldi, L. Mangiaracina, R. Miragliotta, G. Perego, A. and Tumino, A. (2015). "Measuring the benefits of tracking medical treatment through RFId", International Journal of Productivity and Performance Management, Vol 64, No. 2, pp. 175-193.

Golden, B. and Seidmann, A. (2012, "Introduction to the special issue on applications of healthcare operations management", Manufacturing and Service Operations Management, Vol. 14, No. 4, pp. 485-487.

Gray, M. (2017), "Value based healthcare", The BMJ, Vol. 356 2017;356:j437 doi: 10.1136/bmj.j437.

Green, L.V. (2012), "The vital role of operations analysis in improving healthcare delivery", Manufacturing and Service Operations Management, Vol. 14, No. 4, pp. 488-494.

Grindle, M. and Hildebrand, M. (1995), "Building sustainable capacity in the public sector: what can be done?" Public Administration and Development, Vol. 15, pp. 441-463.

Gronoos, C. (2007), “Service Management and Marketing”, John Wiley \& Sons, Chichester. Harvey, J. (2011), Complex Service Delivery Processes: Strategy to Operations, $2^{\text {nd }}$ edition, Quality Press, Milwaukee, WI.

Henrique, D. and Filho, M. (2020). "A systematic literature review of empirical research in Lean 
and Six Sigma in healthcare", Total Quality Management \& Business Excellence, 31:3-4, 429449,

Judd, R. (1964), “The case for redefining services”, Journal of Marketing, Vol. 28, No. 1, pp. 5859.

Kaehne, A., Beacham, A., and Feather, J. (2018), "Co-production in integrated health and social care programmes: A pragmatic model: Managing community care". Journal of Integrated Care, Vol. 26, No. 1, pp. 87-96.

Karwan, K. and Markland, R. (2006), "Integrating service design principles and information technology to improve delivery and productivity in public sector operations: The case of South Carolina DMV." Journal of Operations Management, Vol. 24, pp. 347-362.

King, N. (1998), Template Analysis in G. Symon, \& C. Cassell, (Eds.) "Qualitative Methods and Analysis in Organisational Research", Sage publications, London.

King, N. (2004) Using templates in the thematic analysis of text, in Cassell, C. \& Symon, G. (Eds), "Essential Guide to Qualitative Methods in Organisational Research”, Sage, London.

Kleindorfer, P., Singhal, K. and van Wassenhove, L. (2005), "Sustainable operations management”, Production and Operations Management, Vol. 14, No. (4), pp. 482-492.

Krings, D. Levine, D. and Wall, T. (2006), "The Use of "Lean" in Local Government." Public Management, Vol. 88, No. 8, pp. 12-17.

Long, J. Cunningham, F. and Braithwaite, J. (2013), "Bridges, brokers and boundary spanners in collaborative networks: a systematic review. BMC Health Services Research, Vol. 13, No. 158: Available at https://bmchealthservres.biomedcentral.com/articles/10.1186/1472-6963-13158\#ref-CR17.

Lusch and Vargo McCannon J, and Berwick D.M.. (2011), "A new frontier in patient safety", The Journal of the American Medical Association, Vol. 305, pp. 2221-2. 
Martin, S. (2010), Regulation, In Ashworth, R., Boyne, G. and Entwistle, T. (Eds), Public Service Improvement: Theories and Evidence, pp.36-59. Oxford University Press, Oxford.

McGuire, L. (2012), “Slippery concepts in context. Relationship marketing and public services”, Public Management Review, Vol. 14, pp. 541-555.

McLaughlin, K. Osborne, S. and Ferlie, E. (2002), “New Public Management: Current Trends and Future Prospects”, Routledge, London.

McLaughlin, K., Osborne, S. and Chew, C. (2009), "Developing the marketing function in U.K. public service organizations: the contribution of theory and practice", Public Money and Management, Vol. 29, pp. 35-42.

McNulty, T. and Ferlie, E. (2002) Reengineering Health Care: The Complexities of Organizational Transformation. Oxford University Press, Oxford.

Meredith, J. (1998), "Building operations management theory through case and field research". Journal of Operations Management, Vol. 16 No. 4, pp. 441-454.

Needham, C. and Carr, S. (2009), “Co-production: an emerging evidence base for adult social care Transformation”, SCIE Research briefing 31, Social Care Institute, London.

Newbould, J. Abel, G. Ball, S. Corbett, J. Elliott, M, et al. (2017). "Evaluation of telephone first approach to demand management in English general practice: observational study". The BMJ, Vol. 358:j4197 | doi: 10.1136/bmj.j4197.

NHS England (2013). High quality care now and for future generations: Transforming urgent and emergency care services in England. Page 35-36. Available at: https://www.england.nhs.uk/wp-content/uploads/2013/06/urg-emerg-care-ev-bse.pdf [Accessed 21 ${ }^{\text {st }}$ April 2020].

Okemiri, H. Alo Uzoma, R. Achi, I. Oketa, C. Nnamene, C. and Chima, C. (2020). "Patient Data Integration: A panacea for effective healthcare”, Journal of Computer Science, Vol. 16, No. 2, 
pp 235-248.

Osborne, S. and Brown, L. (2011), "Innovation, public policy and public services: the word that would be king?” Public Administration, Vol. 89, pp. 1335-1350.

Osborne, S. and Strokosch, K. (2013), It takes two to tango? Understanding the co-production of public services by integrating the service management and public administration perspectives, British Journal of Management, Vol. 24, pp. S31-S47.

Osborne, S., Radnor, Z., Kinder, T. and Vidal, I. (2015), “The SERVICE framework: A publicservice- dominant approach to sustainable public services", British Journal of Management, Vol. 26, pp. 1-15.

Osborne, S. Radnor, Z. and Nasi, G. (2013), “A new theory for public services management? Towards a (public) service-dominant approach", American Review of Public Administration, Vol. 43, pp. 135-158.

Osborne, P., Radnor, Z. and Strokosch. K. (2016), "Co-Production and the Co-Creation of Value in Public Services: A Suitable Case for Treatment?” Public Management Review, Vol. 18, No. 5, pp. 639-653.

Palmer, V. Weavell, W. Callander, R. Piper, D. Richard, L. Maher, L. Boyd, H. Herrman, H. Furler, J. Gunn, J. Iedema, R. and Robert, G. (2018). The Participatory Zeitgeist: An explanatory theoretical model of change in an era of coproduction and codesign in healthcare improvement. Journal of Medical Humanities, http://dx.doi.org/10.1136/medhum-2017011398

Papadopoulos, T., Radnor, Z. and Merali, Y. (2011), "The role of actor associations in understanding the implementation of Lean thinking in healthcare", International Journal of Operations \& Production Management, Vol. 31, pp. 167-191.

Parnaby, J. and Towill, D.R. (2008), "Seamless healthcare delivery systems", International 
Journal of Health Care Quality Assurance, Vol. 21, No. 3, pp. 249-273.

Piercy, N. and Brammer, S. (2012), “A complete definition of corporate social responsibility and sustainability", British Academy Report, London

Piercy, N. and Rich, N. (2015), "The relationship between lean operations and sustainable operations", International Journal of Operations \& Production Management, Vol. 35, No. 2, pp. 282-315.

Pil, F. and Rothenberg, S. (2003), "Environmental performance as a driver of superior quality", Production and Operations Management, Vol. 12, No. 3, pp. 404-415.

Pitchforth E, Nolte E, Corbett J, Miani C, Winpenny E, van Teijlingen E, et al. (2017) "Community hospitals and their services in the NHS: identifying transferable learning from international developments - scoping review, systematic review, country reports and case studies". Health Services and Delivery Research, No 5. 19. https://doi.org/10.3310/hsdr05190

Poksinska, B. Fialkowska-Filipek, M. and Engstrom, J. (2016). "Does Lean healthcare improve patient satisfaction? A mixed-method investigation into primary care", BMJ Quality \& Safety, Vol. 26, No 2, dx.doi.org/10.1136/bmjqs-2015-004290.

Presti, L. Testa, M. Marino, V. and Singer, P. (2019). "Engagement in healthcare systems: Adopting digital tools for a sustainable approach", Sustainability, Vol. 11, No. 220 doi.org/10.3390/su11010220.

Proksch, D. Busch-Casler, J. Haberstroh, M. and Pinkwart, A. (2019), "National health innovation systems: Clustering the OECD countries by innovative output in healthcare using a multi indicator approach". Research Policy, 48, pp. 169-179.

Proudlove, N., Moxham, C. and Boaden, R. (2008), "Lessons for lean in healthcare from using Six Sigma in the NHS" Public Money \& Management, Vol. 28, No. 1, pp. 27-34.

Qu, X., Simpson, L. and Stanfield, P. (2011), "A model for quantifying the value of RFID- 
enabled equipment tracking in hospitals", Advanced Engineering Informatics, Vol. 25 No. 1, pp. 23-31.

Radnor, Z. (2010), Review of Business Process Improvement Methodologies in Public Services. Advanced Institute of Management, London.

Radnor. Z. and Bateman, N. (2016), The Role and Substance of Public Service Operations Management in Radnor, Z., Bateman, N. Esain, A. Kumar, M. Williams, S. and Upton, D (Eds), Public Service Operations Management: A research handbook, Routledge, Abingdon, Oxon.

Radnor. Z. and Osborne, S. (2015), Operationalising lean in service, in Radnor, Z., Bateman, N. Esain, A. Kumar, M. Williams, S. and Upton, D (Eds), Public Service Operations Management: A research handbook, Routledge, Abingdon, Oxon.

Radnor, Z. and Osborne, S. (2013), "Lean: a failed theory for public services?" Public Management Review, Vol. 15, pp. 265-287.

Radnor, Z., Osborne, S., Kinder, T. and Mutton, J. (2014), “Operationalising co-production in public services delivery: the contribution of service blue-printing", Public Management Review, Vol. 16, pp.13-20.

Realpe, A. and Wallace, L. (2010), “What is co-production?” Health Foundation, London. Rechel, B. (2020). How to enhance the integration of primary care and public health? Approaches, facilitating factors and policy options, European Observatory of Health Systems and Policies. Available at https://apps.who.int/iris/bitstream/handle/10665/330491/19978073eng.pdf (Accessed 28th April 2020).

Richard, G. (2008), Performance is the Best Politics: How to Create High-Performance Government Using Lean Six Sigma. HPG Press, Fort Wayne.

Seddon, J. and Brand, C. (2008), "Debate: Systems Thinking and Public Sector Performance." 
Public Money and Management, Vol. 28, No. 1, pp. 7-10.

Skalen, P., J. Gummerus, C. von Koskull and Magnusson, P. (2014), "Exploring value propositions and service innovation: a service-dominant logic study", Journal of the Academy of Marketing Science, Vol. 43, pp. 137-158.

Sloan, T, Fitzgerald, A. Hayes, K. Radnor, Z. Robinson, S. and Sohal, A. (2014), "Lean in healthcare - history and recent developments", Journal of Health Organization and Management, Vol. 28, No. 2, doi.org/10.1108/JHOM-04-2014-0064.

Sun, P.R., Wang, B.H. and Wu, F. (2008), "A new method to guard inpatient medication safety by the implementation of RFID”, Journal of Medical Systems, Vol. 32 No. 4, pp. 327-332.

Swedberg, C. (2010), “Apollo Hospital Chennai uses RFID to speed up check-ups”, RFId Journal, June, pp. 1-3, available at: www.rfidjournal.com/articles/view?7659

Taylor, A. and Taylor, M. (2009), "Operations management research: contemporary themes, trends and potential future directions." International Journal of Operations \& Production Management, Vol. 29, No. 1, pp.1316-1340.

The King's Fund, (2015), Health and social care: three priorities for the new government. Available at: http://www.kingsfund.org.uk/projects/new-gov/three-priorities-new-government [Accessed 9th July 2020].

Thune, T. and Mina, A. (2016). "Hospitals as innovators in the health-care system: a literature review and research agenda". Research Policy, Vol. 45, No. 8, pp. 1545-1557.

Vanden Bulte, C., \& Wuyts, S. (2007). Social networks and marketing. Cambridge, MA: Marketing Science Institute.

Verma, R. and Jayashima, K.(2014), "Service delivery innovation architecture: an empirical study of the antecedents and outcomes", IIMB Management Review, Vol. 26, pp.105-121.

Virtanen , P. and Stenvall, J. (2014), "The evolution of public services from co-production to co- 
creation and beyond: New Public Management's unfinished trajectory?", International Journal of Leadership in Public Services, Vol. 10, No. 2, pp. 91 - 107.

Wackerbarth, S. Bishop, S. and Aroh, A. (2020). Lean in Healthcare: Time for evolution or revolution? Journal of Healthcare Quality, doi: 10.1097/JHQ.0000000000000253.

Williams, SJ. (2017), Improving Healthcare Operations: The application of Lean, Agile and Leagility in the design of care pathways, Palgrave MacMillan: London.

Williams, SJ and Radnor, Z. (2017), Using Bandwidths to Visualise and Improve Patient Pathways, Public Money \& Management, Vol. 37, No. 7, pp. 21-28.

Williams, SJ and Caley, L. (2020), Improving Healthcare Services: Co-design, Co-production and Operations, Palgrave MacMillan: London.

Yin, R. K., (2014). Case Study Research: Design and Methods. $5^{\text {th }}$ edition, Sage Publications, London. 
Table 1 SERVICE framework theoretical propositions.

\begin{tabular}{|l|l|}
\hline Proposition 1 & $\begin{array}{l}\text { Public services are systems (not individual organizations) and need to be } \\
\text { governed accordingly (Radnor et al., 2014) }\end{array}$ \\
\hline Proposition 2 & $\begin{array}{l}\text { Public service organizations need to embrace and embed organizational } \\
\text { sustainability in the short term but also realizing this is not sufficient for } \\
\text { long-term sustainability (Boozeman, 2002; Grindle and Hilderbrand, } \\
\text { 1995) }\end{array}$ \\
\hline Proposition 3 & $\begin{array}{l}\text { Long-term relationships are needed to support sustainable public } \\
\text { services, rather than discrete short-term transactions (McGuire, 2012; } \\
\text { McLaughlin et al., 2009) }\end{array}$ \\
\hline Proposition 4 & $\begin{array}{l}\text { Creating sustainable public value for local communities is dependent on } \\
\text { internal efficiencies and external effectiveness (Radnor and Osborne, } \\
\text { 2014; Vidal, 2013). }\end{array}$ \\
\hline Proposition 5 & $\begin{array}{l}\text { Public service organizations need to innovate and disseminate this } \\
\text { across the service system to achieve service effectiveness (Osborne and } \\
\text { Brown, 2011). }\end{array}$ \\
\hline Proposition 6 & $\begin{array}{l}\text { Co-production is at the centre of public service delivery (Osborne and } \\
\text { Strokosch, 2013). }\end{array}$ \\
\hline Proposition 7 & $\begin{array}{l}\text { Public service systems need to generate and capture knowledge to help } \\
\text { deliver and sustain effective service experience (Lusch and Vargo, } \\
\text { 2006; 2014) }\end{array}$ \\
\hline
\end{tabular}

Source: Adapted from Osborne et al., (2015, p. 5) 
Table 2 - Six dimensions of sustainable improvement

\begin{tabular}{|c|c|}
\hline 1. Environment & $\begin{array}{l}\text { The impact on the natural environment of business } \\
\text { operations, the use, reuse and recycling of materials } \\
\text { (resources) for consumption and post consumption. } \\
\text { Piercy and Rich (2014) note the environmental } \\
\text { benefits that lean production can bring in relation to } \\
\text { improved quality and less defects and rework. }\end{array}$ \\
\hline 2. Workforce & $\begin{array}{l}\text { Four sub-dimensions are identified for this } \\
\text { dimension: } \\
\text { workplace operational issues (providing a safe } \\
\text { working environment with good working } \\
\text { conditions), compensation (fair wages and payment), } \\
\text { diversity issues (Non-discrimination in hiring) and } \\
\text { union relations (recognition). } \\
\text { Having an engaged, empowered and well-trained } \\
\text { workforce is a key part of organisational change and } \\
\text { lean improvement (Storey, 1994). }\end{array}$ \\
\hline 3. Supply chain & $\begin{array}{l}\text { How organisations work with the members of their } \\
\text { supply chain is of importance particularly in relation } \\
\text { to labour practices and how they treat suppliers. } \\
\text { Building close, long-term relationships and } \\
\text { transparent levels of communication and information } \\
\text { exchange are some of the factors well established in } \\
\text { the Lean and green supply chain literature (e.g. } \\
\text { Simpson and Power, 2005). }\end{array}$ \\
\hline 4. Community contributions & $\begin{array}{l}\text { This focuses on how organisations make a positive } \\
\text { contribution to the local community, for example } \\
\text { making charitable donations or positively supporting } \\
\text { the community (e.g. Lee and Shin, 2010) }\end{array}$ \\
\hline 5. Governance \& ethics & $\begin{array}{l}\text { This relates to the management of activities such as } \\
\text { socially responsible investment, having a clear and } \\
\text { written ethics policy, and ensuring legal compliance. } \\
\text { As noted above, transparency of information within } \\
\text { the organisation and across organisational boundaries } \\
\text { underpins improvement and sustainability activity. }\end{array}$ \\
\hline 6. Product \& service quality & $\begin{array}{l}\text { Ensuring products and services are safe and fit for } \\
\text { purpose, of good quality and marketing activities are } \\
\text { accurate are examples of this dimension. Improving } \\
\text { operations and product and service quality are central } \\
\text { to lean operations (Womack and Jones, 1996). }\end{array}$ \\
\hline
\end{tabular}

Compiled from Piercy and Brammer (2012) and Piercy and Rich (2015) 
Table 3 Comparison of the SERVICE propositions and dimensions of improvement and sustainability

\begin{tabular}{|c|c|}
\hline SERVICE framework & Sustainable improvement \\
\hline Whole systems approach & This should span the entire supply chain \\
\hline $\begin{array}{l}\text { Embed organizational sustainability in } \\
\text { the short and long-term. }\end{array}$ & $\begin{array}{l}\text { Environmental sustainability should be } \\
\text { part of this along with governance } \\
\text { arrangements and quality improvement. }\end{array}$ \\
\hline Long term relationships are encouraged & $\begin{array}{l}\text { This can include workforce, supply chain } \\
\text { and the wider community }\end{array}$ \\
\hline Establishing sustainable public value & $\begin{array}{l}\text { This requires collaborative relationships } \\
\text { with the supply chain and community } \\
\text { members }\end{array}$ \\
\hline Innovate to achieve service effectiveness & $\begin{array}{l}\text { Innovation can occur in many ways } \\
\text { include environment, supply chain, quality } \\
\text { improvement and investment in the } \\
\text { workforce }\end{array}$ \\
\hline Co-production of service & $\begin{array}{l}\text { This requires the service-user and possibly } \\
\text { the community to be at the centre of } \\
\text { service provision }\end{array}$ \\
\hline $\begin{array}{l}\text { Knowledge creation and mobilization to } \\
\text { enhance the service experience }\end{array}$ & $\begin{array}{l}\text { The generation of knowledge can be } \\
\text { linked internally to the workforce and } \\
\text { externally to supply chain and community } \\
\text { members. Structures and governance } \\
\text { need to be in place to encourage creation } \\
\text { and dissemination of knowledge for } \\
\text { improvement and sustainability of } \\
\text { services }\end{array}$ \\
\hline
\end{tabular}

Source: Compiled by the authors 
Table 4. Selection criteria for HD case study and participants

- Based in the community - majority of health improvement research focuses on acute care (hospital)

- Multi-disciplinary nature of the team - provide different perspectives of the care pathway

- Interaction of team with other health and public services - innovative spirit of team

- Complexity of the care pathway as no clear trajectory of care

- Maturity of team and delivery of family-centred care

- Service users had to have been accessing services for at least 6 months.

- All participants needed to be able to provide consent to participate in the study

Source: Authors 
Table 5 Coding and data examples

\begin{tabular}{|l|l|l|}
\hline $\begin{array}{l}\text { Proposition } \\
\text { approach }\end{array}$ & Code & Example of data \\
\hline & Accessing services & $\begin{array}{l}\text { We are frequently looking } \\
\text { to signpost or accompany } \\
\text { patient wh need to } \\
\text { access other services } \\
\text { (healthcare professional) }\end{array}$ \\
\hline & $\begin{array}{l}\text { The HD MDT are the first } \\
\text { port of call if we need to } \\
\text { access other services. The } \\
\text { team would know or would } \\
\text { find out for us who we } \\
\text { need to contact (relative) }\end{array}$ \\
\hline
\end{tabular}

Source: Authors 
Table 6. Examples of the SERVICE propositions and dimensions of sustainable improvement for the Huntington's disease service

\begin{tabular}{|c|c|}
\hline Proposition & HD Examples \\
\hline 1. System & $\begin{array}{l}\text { Connecting across the service provision (and care supply chain) } \\
\text { to help deliver an integrated service. Examples of working } \\
\text { across health and social care. }\end{array}$ \\
\hline 2. Embed & $\begin{array}{l}\text { One element of embedded organizational sustainability is the } \\
\text { continuity of the team members and ensuring any new members } \\
\text { are properly inducted and well versed in the systems supporting } \\
\text { the HD service. }\end{array}$ \\
\hline 3. Relationships & $\begin{array}{l}\text { Maintaining good relationships with patients is important for the } \\
\text { team. Similarly patients valued the accessibility of the team and } \\
\text { the continuity of the team. Given the nature of the disease the } \\
\text { team works closely with the family as well as the patient. }\end{array}$ \\
\hline 4. Value & $\begin{array}{l}\text { Constantly reviewing the needs of the patients/relatives to help } \\
\text { understand their requirements to maintain function and } \\
\text { independence. With such a complex condition this often } \\
\text { requires multi-agency working which the team may coordinate. }\end{array}$ \\
\hline 5. Innovation & $\begin{array}{l}\text { Innovations are introduced by the team in response to the needs } \\
\text { of patients and relatives for example the monthly group } \\
\text { meetings. Technological solutions tend to be driven by patients } \\
\text { and relatives e.g. use of WhatsApp and Facebook }\end{array}$ \\
\hline 6. Co-production & $\begin{array}{l}\text { Interestingly when the team members were interviewed not all } \\
\text { of them described their service to be co-produced. Yet the } \\
\text { above recent example indicates that the team are moving } \\
\text { towards the coproducing their service. }\end{array}$ \\
\hline 7. Experience & $\begin{array}{l}\text { All team members made reference to trying to improve the } \\
\text { patient experience. Ensuring interventions were available at the } \\
\text { appropriate stage within the patient's health trajectory. In } \\
\text { addition, being clear when assistance was available and when it } \\
\text { was limited. }\end{array}$ \\
\hline \multicolumn{2}{|l|}{ Additional factors } \\
\hline 8. Workforce & $\begin{array}{l}\text { Each team member is assigned a professional mentor. Weekly } \\
\text { meetings are held to discuss new and existing cases. Capacity is } \\
\text { pooled to maintain a responsive service for existing and new } \\
\text { patients and to manage workloads. }\end{array}$ \\
\hline 9. Environmental & $\begin{array}{l}\text { These dimensions were not mentioned directly but the team is } \\
\text { governed by their organisational policies and procedures which } \\
\text { include environment, technology and health \& safety etc. }\end{array}$ \\
\hline
\end{tabular}

Source: Compiled by authors 
Figure 1 - Seven-point SERVICE star of sustainable business model for public service organizations

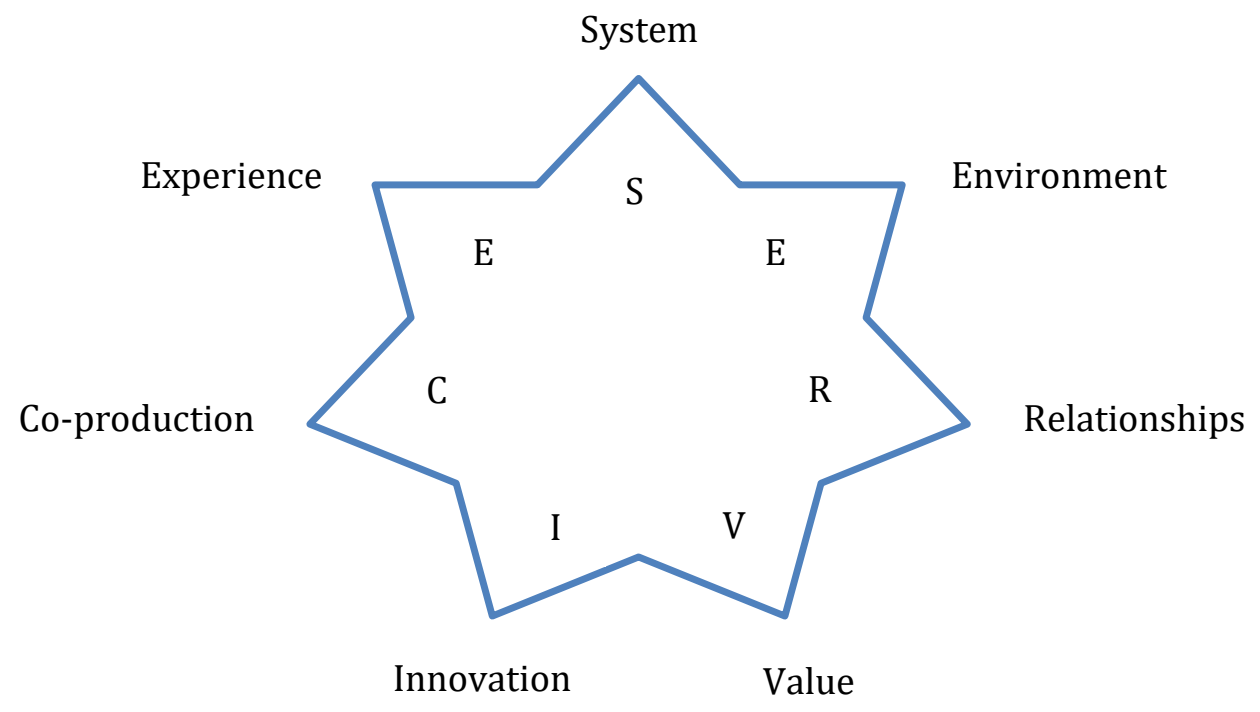

Source: Osborne et al., 2015, p 11 